\title{
CONTESTED IDENTITIES IN COSTA RICA: CONSTRUCTIONS OF THE TICO IN LITERATURE AND FILM. LIZ HARVEY-KATTOU. LIVERPOOL: EDITORIAL DE LA UNIVERSIDAD DE LIVERPOOL, 2018
}

Amanda Alfaro Córdoba

\author{
Recibido: 30-05-2018 - Aceptado: 13-06-2018
}

Publicado como una versión revisada de la investigación que a lo largo de cuatro años la Dra. Liz Harvey realizó sobre Costa Rica, desde el doctorado en la Escuela de Lenguas, Cultura y Sociedad Europeas de la University College London, el libro Contested Identities in Costa Rica: Constructions of the Tico in Literature and Film (Identidades impugnadas en Costa Rica: Construcciones del tico en la literatura y los films) se extiende a lo largo de un amplio corpus. Sus descripciones, análisis y reflexiones dan cuenta de una idea familiar entre los intelectuales del país: las formas de construir pertenencia simbólica difícilmente llegan a consensos, están necesariamente atravesadas por instituciones y procesos normativos que avanzan al lado de fisuras y negociaciones y, específicamente en Costa Rica, exhiben una tendencia dividida geográficamente. Es decir, en el país los discursos institucionales y mediáticos de identidad y normatividad han sido mucho más exitosos en el Valle Central que en los espacios entre cordilleras y costas.

Las geografías operan a través de fuerzas políticas (Sassen) y los bastiones de esas corrientes. De esa manera, aún los espacios que coinciden o se traslapan físicamente pueden construir imaginarios de pertenencia radicalmente distintos de acuerdo con las fuerzas militares, políticas, sociológicas o culturales (de lengua, de religión) que en el espacio físico operan. Sin embargo, en el caso de Centroamérica en general y de Costa Rica en particular, los imaginarios coloniales eurocéntricos funcionaron desde el Pacífico dejando los espacios después de las montañas como un no-lugar, mucho menos receptivos de las narrativas arrojadas por los imaginarios hegemónicos.

El compás de este libro inicia con una idea bastante cristalizada en la tesis doctoral de la Dra. Harvey National Identity Formation in Costa Rican Literary and Film Cultures, 19702015: Constructions and Challenges, es decir, existe un marco imaginario desde el cual la identidad hegemónica costarricense opera, a este marco Harvey lo nombra como tico y, a continuación argumenta, viene a encuadrar los bordes de género, sexualidad, etnicidad y subalternidad que desde el Valle Central costarricense se construyen 
para dar un sentido de pertenencia, afecto y lealtad; así el tico está históricamente construido como masculino, heterosexual, blanco y de clase media-alta. Las fronteras del concepto lo revelan como una moldura rígida que, si bien funcionan como referencia, tendrían que forzar los imaginarios si estos fueran a "caber" dentro de sus contornos; aun así, argumenta Harvey, esa la potencia simbólica del tico se ejercita, negocia y asume sus retos y formas cuando es puesta en escena. La reflexión expuesta en este libro señala que probablemente porque una de las características identitarias más fuertes del mito del tico es su compromiso con la paz y las formas de crear sentido al margen de los enfrentamientos directos -militares, físicos o estratégicos; aunque yo argumentaría no así los indirectos: simbólicos o hasta estructurales- las estrategias retóricas se decantan con vigor desde las tácticas de poder simbólico, poder diplomático o poder suave (soft power). El poder suave se revela como la clave de construcción de imaginarios, pero también de sus fisuras; esta operación fue exitosa en el siglo XX, a través de la literatura, y en el siglo XXI continúa exhibiendo su estrategia de negociación retórica.

Dos formas muy potentes de construir estos bordes son la literatura y los filmes, en este sentido, Harvey escoge la literatura de entre 1970 y 1985 para aportar ejemplos de hasta dónde llega el imaginario en una retrospectiva histórica, por un lado; y, por otro, cómo continúan operando en el siglo XXI, ahora por medio de las narrativas fílmicas.

La naturaleza liminal de este libro hace que tanto su corpus como las herramientas teóricas con las cuales realiza el análisis sean ricas en ideas y metáforas; así, los cuentos y la novela que revisa representan narrativas construidas desde el feminismo (Simbiosis del encuentro, A los payasos todos los quieren de Carmen Naranjo), espectros de preferencia sexual abiertos (La lluvia. El silencio. La música y El hilo del viento de Alfonso Chase) o personajes de identidades raciales salidas de la norma blanca o mestiza para ingresar en el análisis minucioso del racismo (Los cuatro espejos de Quince Duncan). Los filmes también revisan una amplia variedad de representaciones, desde la cultura joven y la ciudad de San José en clave adolescente (en Gestación de Esteban Ramírez), pasando por la fluidez queer y las formas de establecer lazos familiares y afectos (en Abrázame como antes de Jurgen Ureña) hasta llegar a la puesta en escena del mito del excepcionalismo costarricense (Maykol Jordan de viaje perdido de Miguel Gómez) y, de nuevo, al juego de espejos entre un consumo del Caribe y la otredad que este representa desde la mirada de una josefina (Dos aguas de Patricia Velázquez).

El análisis narrativo y estético echa mano de las teorías de la crítica fílmica feminista y el habitus sociológico, pasando por conceptos de las teorías poscoloniales que describen e interrogan el eurocentrismo; de esa manera, Contested Identities in Costa Rica... entrelaza lecturas de las formas, retóricas y subtextos del corpus desde referencias locales, regionales y globales, en un ejercicio de destreza para relacionar las 
nociones de normativización construidas por medio del poder suave y los matices que fisuran estas fronteras desde las propias narraciones, se manifiesten estas por medio de cuentos, novela o películas.

En su conclusión, Harvey señala cómo el mito del tico, lejos de ser excepcional, es la norma de las construcciones simbólicas occidentales mientras, paradójicamente, ofrece la ilusión de la excepcionalidad. De esta manera, apunta:

Como en muchas partes del mundo, los conceptos normativos y hegemónicos de lo que constituye identidad nacional en Costa Rica han aspirado por mucho tiempo a la supremacía blanca, patriarcal y heteronormativa. En este caso en particular, el orgullo patriótico en los orígenes míticos de la nación, así como el de su fervor omnívoro marcan al país como excepcional, especialmente en comparación con sus vecinos, este orgullo se ha cristalizado en el término tico (Harvey, 2018, 201, traducción propia).

Ahora bien, el libro analiza las narraciones y reflexiona sobre sus propuestas de personajes, situaciones, problemas y puntos de vista dejando en evidencia que, si bien las normas nacionales que operan por medio del mito del tico se mantienen vivas en muchos de los imaginarios del país, estas enfrentan retos frescos desde los textos estudiados. El hecho de que estas historias amenacen la camisa de fuerza vallecentralista -"el tico es excluyente y exclusivo, pues pone a la patria por encima de cualquier otra cosa", dice Harvey (2018, 201, traducción propia)- no garantiza mucho más que un ejercicio de expresión; sin embargo, la autora encuentra que la consideración y el gusto que las audiencias muestran por estas otras historias, que rechazan tales exclusiones, arrojan apreciaciones que desafían las rígidas políticas identitarias que desde las instituciones hegemónicas se han construido -y se siguen construyendo- para el país. En una operación de observación transversal en el tiempo, Harvey prueba que estas fisuras ya se observaban en las narrativas de la década de 1970 y que, aunque durante estas cuatro décadas fueron invisibilizadas por las mismas instituciones, muestran ideas de continuidad en una especie de corriente subterránea y transparente que se podría describir como contracultura.

Los espacios físicos tanto en los cuentos y la novela del siglo pasado como en las películas contemporáneas representan una ciudad que quiebra las imágenes de promoción turística tan reconocidas afuera de Costa Rica. Para el caso de la ciudad, argumenta Harvey, la imagen turística se muestra erosionada tanto en la novela Los cuatro espejos como en las películas contemporáneas Gestación, o Abrázame como antes; en palabras de la crítica: "la ciudad se confunde con la discriminación. En estas impresiones, el centro dominante del país se muestra como un lugar áspero, descarnado donde la cultura joven predomina, la violencia acecha y los enfrentamientos sociales prevalecen" (Harvey, 2018, 208, traducción propia). El espacio afuera de la ciudad tampoco se salva de la decadencia: en El hilo, el bosque mágico es destruido por la violencia espontánea que los 
propios hermanos del protagonista ejercen y en Dos aguas la inquieta atmósfera señala el peligro en los espacios construidos desde el mercado como "idílicos".

Esta publicación de la Editorial de la Universidad de Liverpool tiene como virtud la formulación de un rico marco teórico que analiza un corpus diverso y amplio, arrojando una perspectiva flexible y hábil que permite establecer conexiones entre diferentes géneros y a lo largo de distancias temporales, pero siempre en los límites físicos de la microgeografía costarricense. Al hacerlo, conversa con la materialidad de su propia producción, poniendo en evidencia las dinámicas de creación que permiten la existencia misma de estos textos y de las grietas simbólicas y materiales que dejan en evidencia. Además, construye un puente discursivo, pues deja ver las influencias regionales, continentales y globales en el fenómeno que trae a escrutinio.

Este puente podría revelar preguntas y nociones más complejas si considerara discusiones ya avanzadas en los círculos intelectuales del país, por ejemplo, el libro y los artículos de Alexander Jiménez Matarrita sobre el discurso filosófico y la invención de Costa Rica o el estudio desarrollado por Laura Álvarez Garro acerca del mito democrático costarricense. Lo anterior no quiere decir que Contested Identities in Costa Rica... ignore las publicaciones que se hacen desde Costa Rica sobre el poder suave o las construcciones identitarias locales, Harvey conoce y dialoga con los estudios de Álvaro Quesada Soto, sobre literatura costarricense, los libros de María Lourdes Cortés sobre cine regional y costarricense y los libros y artículos de Carlos Sandoval sobre migraciones centroamericanas y la construcción de otredades internas y regionales en Costa Rica así como los libros de Iván Molina Jiménez y Steven Palmer sobre el racismo y las operaciones identitarias en el país. Como todo libro, Contested Identities in Costa Rica... llega hasta un punto e invita a continuar la conversación a la luz de los cambios sociales, retóricos y legales que se avanzan en el país. Acaso con optimismo el libro visualiza las resistencias contra la violencia epistémica y pone en evidencia estos procesos, así como el papel del poder suave en ellos, en los tres espacios: local, regional y global.

\section{Bibliografía}

Harvey, E. National Identity Formation in Costa Rican Literary and Film Cultures, 19702015: Constructions and Challenges (tesis doctoral). University College London, 2015.

Harvey-Kattou, L. Contested Identities in Costa Rica: Constructions of the Tico in Literature and Film. Liverpool: University of Liverpool Press, 2018.

Sassen, S. Globalizations. International Affairs, 11(4): 461-472. 2014. http://doi.org/10.1080/14747 731.2014.951206 
Amanda Alfaro Córdoba. Costarricense. Candidata a Doctora por la University College London (UCL), profesora adjunta en la Universidad de Costa Rica. Su investigación sobre producción cinematográfica, estética y consumo en Centroamérica y el Caribe avanza dentro del programa de doctorado con salida documental en la Escuela de Lenguas, Culturas y Sociedad Europeas (SELCS) y el Centro de Investigación Multicultural e Interdisciplinaria (CMII). Ha sido directora de televisión, guionista y productora en el Sistema Universitario de Televisión de la Universidad de Costa Rica y para el proyecto "Know it Wall" de UCL.

Contacto: amanda.alfarocordoba@gmail.com

ORCID: 0000-0002-3367-5325 
